\title{
Potential of mean force between ions in infinitely diluted simple short-range models of aqueous electrolytes
}

\author{
L.Vlček ${ }^{1}$, I.Nezbeda ${ }^{1,2}$ \\ 1 E. Hala Laboratory of Thermodynamics, ICPF, Acad. Sci., \\ Rozvojova 135, 16502 Prague 6 - Suchdol, Czech Republic \\ 2 Physics Department, J. E. Purkyně University, \\ 40096 Ústí n. Lab., Czech Republic
}

Received January 6, 2005

\begin{abstract}
As an attempt to assess the effect of the long-range electrostatic interactions in solutions of electrolytes, a simple short-range model (SSM) of electrolytes made up of primitive water and primitive ions (i. e., ions whose Coulombic interaction with water has been replaced by a triangular-well interaction) has been considered to compute the potential of mean force. The sizes of the primitive ions have been set so as to approximate realistic $\mathrm{NaCl}$, Lil, and $\mathrm{CsCl}$ electrolytes. It is shown that despite the missing longrange Coulombic interaction the model captures the basic features of real electrolytes while the indirect, i.e. water mediated, potential of mean force in the SSM is in qualitative agreement with that of realistic models.
\end{abstract}

Key words: aqueous electrolytes, simple short-range model of electrolytes, primitive water, primitive ions, potential of mean force

PACS: $05.20 . J j$

\section{Introduction}

Recent extensive investigations of the effect of the range of interactions on properties of polar and associating fluids have lead to an unambiguous conclusion that the structure of pure fluids, given in terms of a complete set of the site-site correlation functions, is determined primarily by short-range interactions (regardless of their origin) and that the long-range part of the Coulombic interactions, regardless of their strength, may be treated as a perturbation [1]. Although this conclusion seems to remain valid also for a number of other properties of pure fluids, their validity for mixtures is questionable and remains an open problem [2]. Particularly questionable seems their extension to systems with free charges. Thus, the next evident step along the path of investigations of the effect of the range of interactions on the properties 
of fluids is to consider aqueous solutions of electrolytes.

With only a few attempts to account for the effect of the molecular nature of the solvent, typically water (see e.g. [3] and references therein), solutions of electrolytes have been so far considered at the McMillan-Mayer level [4]. It means that the solute is considered explicitly as a collection of molecules but the solvent is treated as dielectric continuum. Thus, to go beyond the McMillan-Mayer level means to consider explicitly the molecular nature of the solvent as well.

In the light of the results for pure polar and associating fluids, and solutions of non-electrolytes, the basic question to be asked is whether it is the long-range part of the Coulombic interactions which gives rise to all observed properties of electrolytes and is thus indispensable, or whether it can be omitted at a zeroth level approximation (and at certain conditions). The latter possibility would make it possible to use, at least in theoretical calculations, a simple model of electrolytes with an explicit molecular model of water but without any long-range electrostatic forces and, eventually, to develop a theory for such a model.

Recently we introduced a simple short-range model (SSM) of electrolytes and investigated an infinitely dilute solution of spherical molecules in primitive water [5]. In the SSM the solute molecule, called ion, is a hard sphere with a short-range interaction tail (which may be either repulsive or attractive) to mimic the shortrange effects of the Coulombic interactions between an ion and a water molecule at short separations. We carried out an imaginary hydration experiment on an infinitely diluted solution (one ion in dense primitive water) whose results were in agreement with realistic models [6] and that also provided a simple and direct interpretation of the structure breaking/enhancement phenomena in terms of the site-site correlation functions [7].

As a next step along the line of a potential use of the SSM, we consider in this paper a pair of ions and compute the indirect part of the potential of mean force (PMF). Although we set some parameters so as to roughly mimic the realistic ions, this attempt should be viewed as a feasibility study examining the effect of the long-range forces in an inverse way. In other words, instead of starting with a full realistic model and then passing to its gradual simplification (shortening) we begin immediately with a simple short-range model. The main reason for this approach is primarily technical because otherwise the number of parameters to play with would make the computations extremely time consuming and tedious.

\section{Basic definitions and computational details}

The realistic potentials of water and ions used in the present simulations are common site-site potentials composed of the Lennard-Jones (LJ) and Coulombic terms,

$$
u(1,2)=\sum_{i \in\{1\}} \sum_{j \in\{2\}}\left\{4 \epsilon_{i j}\left[\left(\frac{\sigma_{i j}}{r_{i j}}\right)^{12}-\left(\frac{\sigma_{i j}}{r_{i j}}\right)^{6}\right]+\frac{q_{i}^{(1)} q_{j}^{(2)}}{\left|\mathbf{r}_{i}^{(1)}-\mathbf{r}_{j}^{(2)}\right|}\right\}
$$


where $i$ and $j$ denote interaction sites, $\epsilon_{i j}$ and $\sigma_{i j}$ are the parameters of the LJ potential, and $q_{i}$ is the charge on site $i$. Specifically, for compatibility with available simulation data, for the water-water interaction we have chosen the SPC/E model [8], and the LJ parameters of ion-water potentials are taken from reference [9]; the parameters of the ion-ion interaction, $\epsilon_{\mathrm{II}}$ and $\sigma_{\mathrm{II}}$, are derived from the usual combining rules,

$$
\epsilon_{i j}=\left(\epsilon_{i i} \epsilon_{j j}\right)^{1 / 2}, \quad \sigma_{i j}=\left(\sigma_{i i}+\sigma_{j j}\right) / 2 .
$$

The parameters of the considered potentials are summarized in table 1.

Table 1. Parameters of the realistic models of water and ions.

\begin{tabular}{|c|c|c|c|c|c|c|}
\hline model & site & $\epsilon_{i i} / k_{\mathrm{B}}[\mathrm{K}]$ & $\left.\overline{\sigma_{i i}[\AA]}\right]$ & $\epsilon_{i \mathrm{O}} / k_{\mathrm{B}}[\mathrm{K}]$ & $\left.\overline{\sigma_{i \mathrm{O}}[\AA]}\right]$ & $\overline{q_{i}[\mathrm{e}]}$ \\
\hline \multirow{2}{*}{$\mathrm{SPC} / \mathrm{E}$} & $\mathrm{O}$ & 78.205 & 3.169 & 78.205 & 3.169 & -0.8476 \\
\hline & $\mathrm{H}$ & 0.0 & 0.0 & 0.0 & 0.0 & 0.4238 \\
\hline \multirow[t]{5}{*}{ Ions } & $\mathrm{Li}^{+}$ & 83.037 & 1.505 & 80.583 & 2.337 & 1 \\
\hline & $\mathrm{Na}^{+}$ & 50.327 & 2.583 & 62.374 & 2.876 & 1 \\
\hline & $\mathrm{Cs}^{+}$ & 50.327 & 3.883 & 62.374 & 3.526 & 1 \\
\hline & $\mathrm{Cl}^{-}$ & 50.327 & 4.401 & 62.374 & 3.785 & -1 \\
\hline & $\mathrm{I}^{-}$ & 50.327 & 5.167 & 62.374 & 4.168 & -1 \\
\hline
\end{tabular}

At the level of simple models the short-range repulsive interaction between the sites of the water molecules are approximated by a hard sphere interaction and the attractive interaction between the unlike sites by a square-well interaction to mimic hydrogen bonding. Further, the primitive models derived in this way also respect the geometry of the realistic parent models and there are recipes to set the parameters of the models [10-12]. Primitive water PM/SPC-E, descending from the SPC/E model is of the following form [12]:

$$
u_{\mathrm{PM} / \mathrm{SPC}-\mathrm{E}}(1,2)=\sum_{\substack{i, j \in\{\mathrm{O}, \mathrm{H}\} \\ i=j}} u_{\mathrm{HS}}\left(\left|\mathbf{r}_{i}^{(1)}-\mathbf{r}_{j}^{(2)}\right| ; d_{i j}\right)+\sum_{\substack{i, j \in\{\mathrm{O}, \mathrm{H}\} \\ i \neq j}} u_{\mathrm{SW}}\left(\left|\mathbf{r}_{i}^{(1)}-\mathbf{r}_{j}^{(2)}\right| ; \lambda\right),
$$

where the summation in the first term runs over the pairs of like sites and in the second term over the pairs of unlike sites,

$$
u_{\mathrm{HS}}\left(r_{12} ; \sigma\right)= \begin{cases}+\infty, & \text { for } r_{12}<\sigma \\ 0, & \text { for } r_{12}>\sigma\end{cases}
$$

and

$$
u_{\mathrm{SW}}\left(r_{12} ; \lambda\right)= \begin{cases}-\epsilon_{\mathrm{HB}}, & \text { for } r_{12}<\lambda, \\ 0, & \text { for } r_{12}>\lambda .\end{cases}
$$

The parameters of the model are given in table 2 .

The ion-water molecule interaction is also considered in the form of a site-site potential which, in the case of the PM/SPC-E solvent, assumes the form

$$
u_{\mathrm{I}-\mathrm{W}}=u_{\mathrm{HS}}\left(\left|\mathbf{r}_{\mathrm{I}}-\mathbf{r}_{\mathrm{O}}^{(2)}\right| ; d_{\mathrm{IO}}\right)+\sum_{j \in\{\mathrm{O}, \mathrm{H}\}} u_{\mathrm{TW}}\left(\left|\mathbf{r}_{\mathrm{I}}-\mathbf{r}_{j}^{(2)}\right| ; R_{\mathrm{TW}}\right),
$$




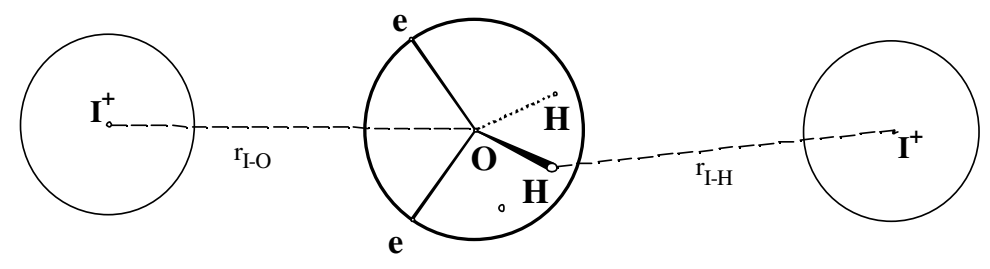

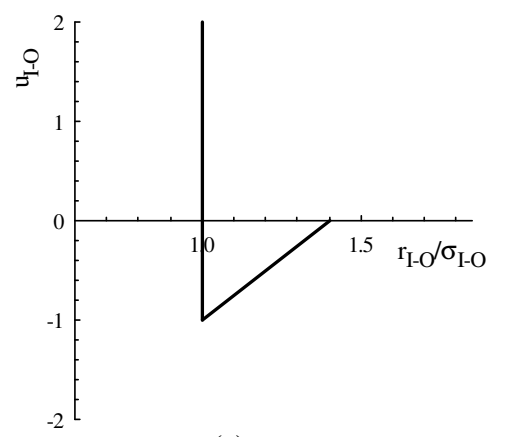

(a)

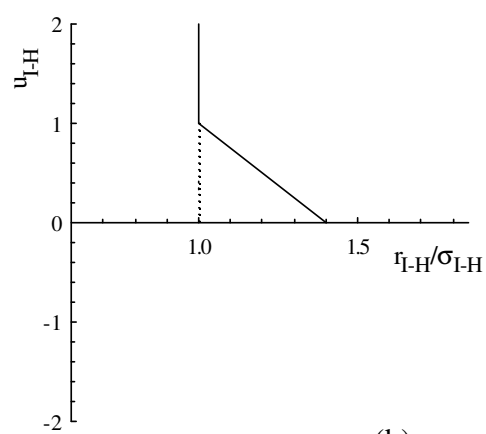

(b)

Figure 1. Schematic representation of the solute and (5-site) water molecules in the simple short-range models of aqueous solutions of electrolytes (top), and the attractive solute-water interaction [bottom (a)] and repulsive solute-water interaction [bottom (b)].

where $\mathbf{r}_{I}$ refers to ions, the summation runs over appropriately chosen sites on the water molecule, and

$$
u_{\mathrm{TW}}\left(r ; R_{\mathrm{TW}}\right)= \begin{cases}\epsilon_{\mathrm{TW}} q_{i} q_{j} \frac{R_{\mathrm{TW}}-r}{R_{\mathrm{TW}}} & \text { for } 0<r<R_{\mathrm{TW}} \\ 0 & \text { for } r>R_{\mathrm{TW}} .\end{cases}
$$

Here $q_{i}$ is the charge on the interaction site $i, R_{\mathrm{TW}}$ is the range of the TW interaction, and $\epsilon_{\mathrm{TW}}$ is a parameter which relates the strength of the TW interaction to the SW interaction. Since there is no obvious clue to set this parameter, $\epsilon_{\mathrm{TW}}$ was set to such a value that for $d_{\mathrm{IO}}=1.0, R_{\mathrm{TW}}=2.0$, and for charges $q_{\mathrm{H}}$ and $q_{\mathrm{O}}$, the energy at the contact is the same as the energy of the hydrogen bond, $\epsilon_{\mathrm{HB}}$. The ion-water potential is schematically presented in figure 1.

In the case considered here we place charges at the O-site and $\mathrm{H}$-sites only, which is also a common practice for realistic models. We further set $d_{\mathrm{IO}}=\left(d_{\mathrm{II}}+d_{\mathrm{OO}}\right) / 2$, where $d_{\text {II }}$ are derived by the hybrid Barker-Henderson method (for details see, e.g., [10]). The parameters of the SSM are summarized in table 2.

The potential of the mean force, $u_{\mathrm{MF}}$, is defined by a generalization of the lowdensity limit of the pair correlation function,

$$
g_{\text {ion-ion }}(r)=\mathrm{e}^{-\beta u_{\mathrm{MF}}}=\mathrm{e}^{-\beta\left[u_{\text {ion-ion }}+u_{\text {indir }}\right]},
$$


Table 2. Parameters of the primitive models of water and ions.

\begin{tabular}{|r|cccccc|}
\hline model & site & $d_{i i}[\AA]$ & $d_{i i} / d_{\mathrm{OO}}$ & $d_{i \mathrm{O}}[\AA]$ & $d_{i \mathrm{O}} / d_{\mathrm{OO}}$ & $q_{i}$ \\
\hline PM/SPC-E & $\mathrm{O}$ & 2.642 & 1.0 & 2.642 & 1.0 & 0.84 \\
& $\mathrm{H}(\mathrm{X})$ & 2.087 & 0.79 & 1.638 & $0.62^{1}$ & 0.42 \\
\hline Ions & $\mathrm{Li}^{+}$ & 1.255 & 0.475 & 1.948 & 0.737 & 1.0 \\
& $\mathrm{Na}^{+}$ & 2.153 & 0.815 & 2.398 & 0.908 & 1.0 \\
& $\mathrm{Cs}^{+}$ & 3.236 & 1.225 & 2.940 & 1.113 & 1.0 \\
& $\mathrm{Cl}^{-}$ & 3.670 & 1.389 & 3.156 & 1.194 & -1.0 \\
& $\mathrm{I}^{-}$ & 4.306 & 1.630 & 3.475 & 1.315 & -1.0 \\
\hline
\end{tabular}

${ }^{1}$ range of the SW attraction, $\lambda$.

where $g$ is the pair correlation function, $u_{\text {ion-ion }}$ is the potential of the direct ion-ion interaction, and $u_{\text {indir }}$ is an indirect, water mediated part of $u_{\mathrm{MF}}$.

We performed Monte Carlo simulations in an NVT ensemble in a similar manner for both realistic and primitive potentials. In both cases there were 511 water molecules in the simulation box (SPC/E or PM/SPCE), and a pair of ions. The perturbation methodology was used to compute $u_{\mathrm{MF}}$ between the ions or ion-like particles. The perturbation method is based on a relation for the free energy difference, $\Delta F$, between a reference system, denoted by subscript 0 , and the system of interest [13]:

$$
\beta \Delta F=\beta\left(F-F_{0}\right)=-\ln \frac{Q}{Q_{0}}=-\ln \langle\exp (-\beta \Delta u)\rangle_{0},
$$

where $\beta=1 /\left(k_{\mathrm{B}} T\right), T$ is temperature, $k_{\mathrm{B}}$ is the Boltzmann constant, and $\Delta u$ is the potential energy difference between the reference and perturbed system. The reference system consists of water molecules and the pair of ions held at a constant separation. The perturbation is generated by a virtual displacement of the two solute particles: the interparticle separation is changed by $\pm \Delta r$ and the corresponding terms $\exp \left[-\Delta u /\left(k_{\mathrm{B}} T\right)\right]$ are accumulated. The PMF between the ions is then obtained by integration of the averaged differences. To make the sampling of the configurational space in the vicinity of the ion pair more efficient, the preferential sampling was used [14].

The simulations were arranged in cycles, each cycle consisting of $3 \times N$ oneparticle steps. After each cycle, virtual displacements were generated with increasing/decreasing ion-pair separation. The length of the displacements was $\Delta r=$ $0.01 \AA$ for realistic potentials and $0.005 d_{\mathrm{OO}}$ for primitive potentials. Free energy difference, (9), for each separation was obtained by averaging over $5 \times 10^{4}$ cycles at every $2 \Delta r$ from contact to $8.0 \AA$. All curves were normalized to zero for the maximum ion-ion separation measured. 


\section{Results and discussion}

In [5] we set, for simplicity, $R_{\mathrm{TW}}=1.4 \mathrm{~d}_{\mathrm{OO}}$, i.e. the same value as $\lambda$ for primitive water. It is, however, evident that the range of the ion-water interaction should considerably affect the properties of the system. Since there is neither any rule nor at least a hint where to truncate this interaction, several following values for $R_{\mathrm{TW}}^{*} \equiv R_{\mathrm{TW}} / d_{\mathrm{OO}}$ are considered: $1.5,2.0,2.5$, and 3.0. Density is set to that of pure water at ambient conditions, and $\beta=6$; at these conditions the structure of primitive water is very close to that of real water at ambient conditions [12].

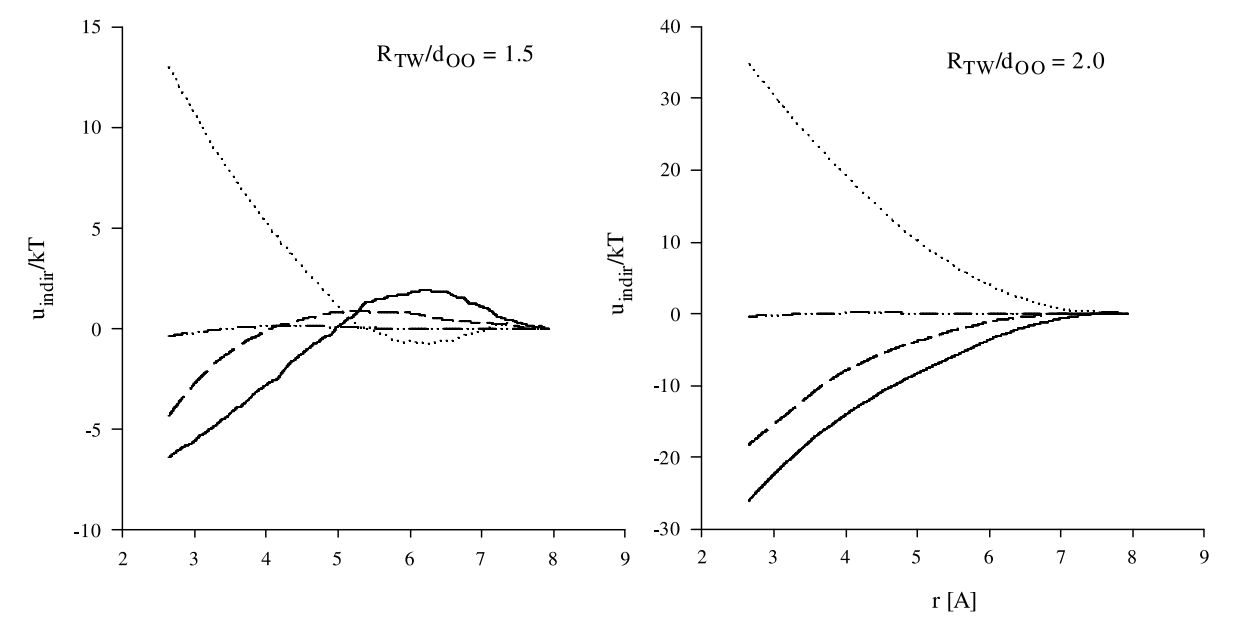

Figure 2. Dependence of the indirect part of the PMF on the range of the ionwater interaction in the SSM electrolyte. (Full line: cation-cation; dashed line: anion-anion; dotted line: anion-cation; dashed-double dotted line: hard spherehard sphere).

First, we assess a qualitative dependence of the ion-ion PMF on the range of the ion-water interaction. Simulations with two equal-sized ions with diameter $d_{\mathrm{II}}=d_{\mathrm{OO}}$ and the range $R_{\mathrm{TW}}^{*}$ equal to 1.5 and 2.0 have been carried out. The former case corresponds to the boundary between the first and second hydration shells, in the latter case the ion-water interaction reaches half of the second hydration shell. The results are shown in figure 2 along with the PMF between two hard spheres of the same diameter. From the comparison of these results it follows that for smaller, near to contact separations, the PMF of all the ion pairs is qualitatively correct: like ions are attracted while unlike are repelled. At larger separations, however, the systems with $R_{\mathrm{TW}}^{*}=1.5$ exhibit a minimum for oppositely charged ions and for identically charged ions a maximum at the ion separation $r_{\text {II }} \approx 2$. Comparing it with the shape of the PMF for the system with $R_{\mathrm{TW}}^{*}=2.0$ it is clear that these extremes are artifacts of the too short range of the ion-water interactions. Moreover, for larger ions (of the size $d_{\mathrm{II}} / d_{\mathrm{OO}}>1$ ), the range $R_{\mathrm{TW}}^{*}=1.5$ would be too short and most of the Coulombic-like interactions would be shielded by the HS repulsions between the cores of the ion and water oxygen. Therefore, in further studies only the values $R_{\mathrm{TW}}^{*}=2.0$ and higher are considered. 
It is also worth to note the difference in the indirect interaction between the pair of cations and anions. The former are, in the used model, attracted one to another more strongly than the latter. Since the ions themselves are symmetrical, the difference should be attributed to the asymmetry of the water molecules.
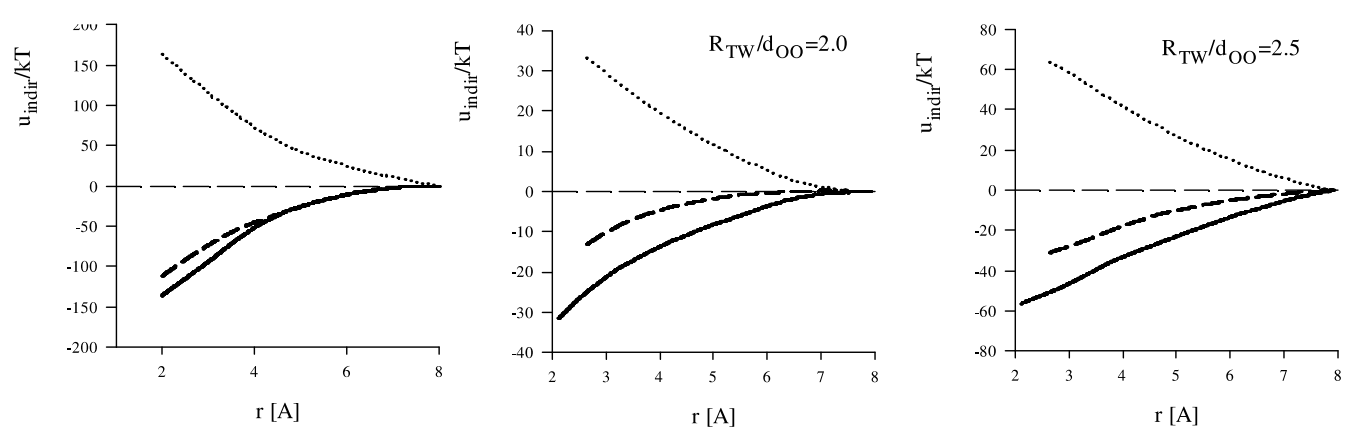

Figure 3. Comparison of the $\mathrm{PMF}$ in a realistic model of $\mathrm{NaCl}$ (the leftmost graph) with that in the SMM electrolyte of different ion-water interaction range (graphs on the left). [Full line: cation-cation; dashed line: anion-anion; dotted line: anion-cation].
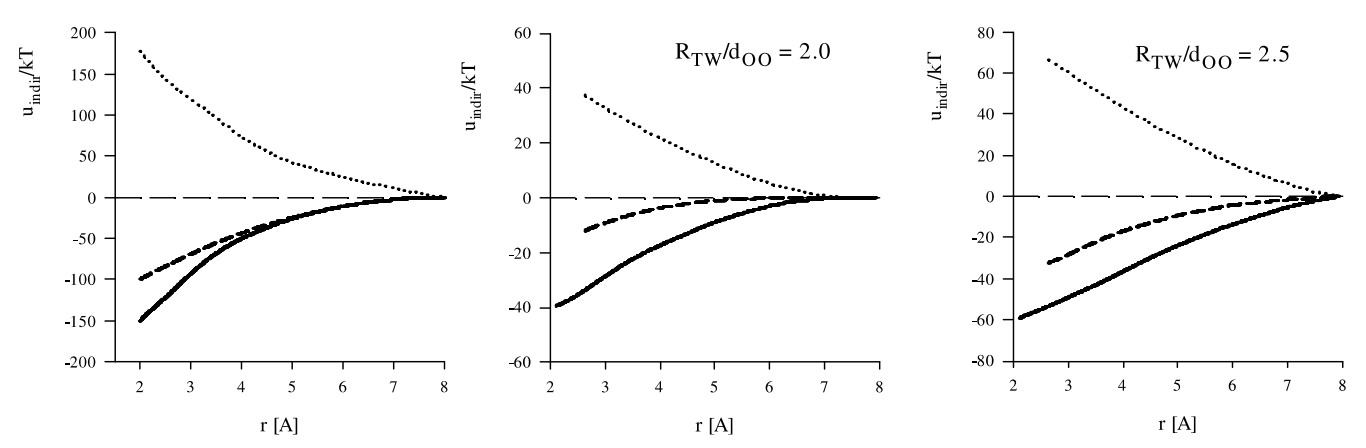

Figure 4. The same as figure 3 for LiI.
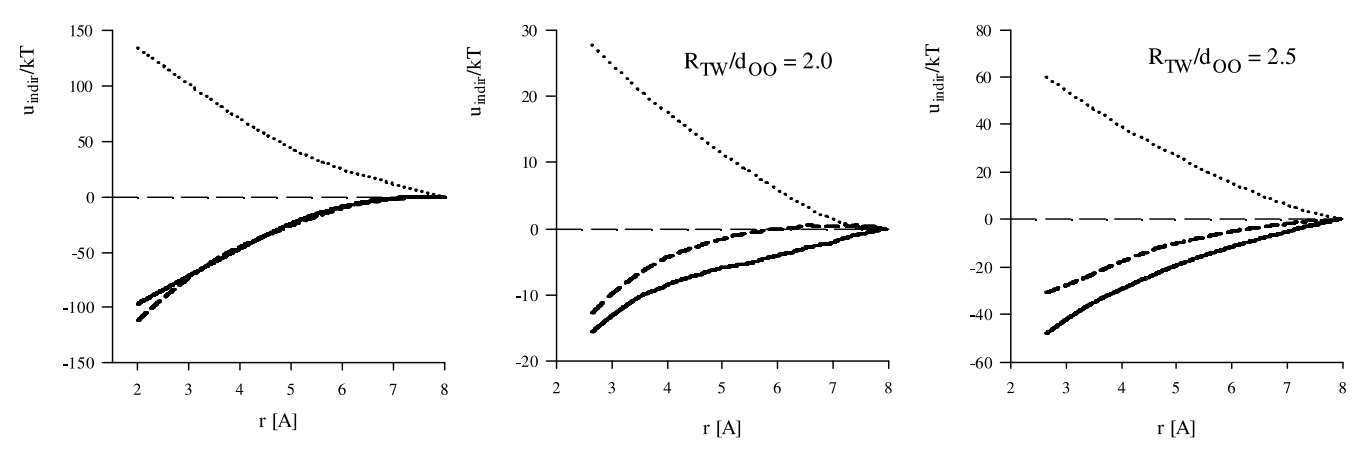

Figure 5. The same as figure 3 for $\mathrm{CsCl}$. 
To study the effect of the ion size, i.e. the range of the HS repulsion, on the PMF, we use a realistic representation of ions with the HS diameters related to real ions (see table 2). Besides the common pairs of $\mathrm{NaCl}$, the $\mathrm{LiI}$ and $\mathrm{CsCl}$ pairs are chosen to represent ions with the maximal and minimal difference between their diameters, respectively. In figures 3, 4, and 5 we compare the indirect part of the PMF of realistic ions to that of primitive models with two ranges of the TW potential, $R_{\mathrm{TW}}^{*}=2.0$ and 2.5. (We have also considered the range $R_{\mathrm{TW}}^{*}=3.0$ but the results do not show any different and significant trend; they are therefore not shown here for the sake of space.) It is seen that the shape of the primitive potential is in qualitative agreement with the realistic one for the both $R_{\mathrm{TW}}$ considered, and it improves with the increasing range of the TW interaction. A certain (quantitative) difference is best seen for larger anions, in which case the shorter range causes a substantial part of the TW interaction to be shielded by the HS repulsion between the ion and oxygen. Since the longer range also means stronger water-ions interactions, the strength of the indirect interaction also increases. However, the actual strength can also be changed by varying the parameter $\epsilon_{\mathrm{TW}}$ and, therefore, the absolute value of the PMF is not very important. The figures corresponding to primitive potentials show that the range of the indirect interaction is larger than the range of the direct effect of the TW potential. This means that beyond the separation given by $R_{\mathrm{TW}}$, the PMF between ions is given purely by the indirect, water-mediated part of interaction, which leads to unphysical behavior: like ions are attracted and unlike are repelled. This contrasts with realistic electrolyte solutions in which both direct and indirect interactions between ions are long-ranged and for oppositely charged ions are in a fine balance and approximately compensate each other. This could mean certain limitations for the use of finite range potentials mimicking infinite Coulombic interactions. As for the PMF dependence on the size of the ionic hard cores, the comparison of the indirect interactions for $\mathrm{Li}^{+}$pairs and $\mathrm{Cs}^{+}$pairs shows that smaller cations are attracted strongly as well as the interaction of two $\mathrm{Cl}^{-}$ions is weaker than for $\mathrm{I}^{-}$. This is a direct consequence of a stronger interaction between water and ions as they approach shorter separations.

\section{Conclusions}

As a feasibility study to explore a possibility to extend the recently introduced simple short-range model of electrolytes beyond the infinitely dilute range, we have evaluated the indirect (i.e., water mediated) part of the potential of mean force for three types of electrolytes mimicking realistic $\mathrm{NaCl}$, LiI, and $\mathrm{CsCl}$ electrolytes. The main ingredient of the model is primitive water used as a molecular model of the solvent. This model, despite its simplicity, has been found to describe the structure of pure water at a semiquantitative level [12], as well as to be able to correctly describe the hydration of, at least, small spherical particles, such as the hard cores of ions [15]. Moreover, a good theoretical description of the thermodynamic properties of pure primitive models and their mixtures with hard-body particles is available [16].

The purpose for focussing on the indirect part of the PMF has been an attempt 
to isolate the effect of the molecular nature of the solvent on the potential of mean force between ion pairs. No systematic investigation of the PMF dependence on the strength of the ion-water potential has therefore been carried out. A question about the convenience of the considered choice of this strength remains thus open and further study determining optimal values will be needed.

To study the effect of the truncation of the Coulombic interactions at a simple level, we used a triangular-well potential of varying range for the ion-water interaction. It turns out that if the range of this interaction extends at least to the second hydration shell, then the model captures, qualitatively, the main features of the indirect part of the PMF of real electrolytes. However, in our previous general study [2] it was found that in real electrolyte solutions a subtle balance exists between the direct and indirect parts of the ion-ion interaction and that a simple truncation of the long-range Coulombic interactions may lead to an unphysical behavior. It will be therefore necessary to study these effects in a systematic way to find the basis of such a balance and to find a suitable way to minimize the artifacts of truncation; the model considered in this paper seems an ideal model to be used for this purpose.

\section{Acknowledgement}

This work was supported by the Grand Agency of the Czech Republic (Grant No. 203/02/0764).

\section{References}

1. Nezbeda I. Mol. Phys., 2005, 103, 59-76.

2. Nezbeda I., Kolafa J. Ionic Soft Matter, eds. D. Henderson, M. Holovko. Kluwer, in press.

3. Chialvo A.A., Cummings P.T., Simonson J.M., Mesmer R.E., J. Chem. Phys., 1999, 110, 1064-1074; Llano-Restrepo M., Chapman W.G., J. Chem. Phys., 1994, 100, 83218339.

4. Lee L.L. Molecular Thermodynamics of Nonideal Fluids. Butterworth, London, 1988.

5. Nezbeda I. Mol. Phys., 2001, 99, 1631-1639.

6. Lynden-Bell R.M., Rasaiah J.C., J. Chem. Phys., 1997, 107, 1981-1991.

7. Nezbeda I., J. Mol. Liquids C, 2003, 103-104, 309-317.

8. Berendsen H.J.C., Grigera J.R., Straatsma T.P., J. Phys. Chem., 1987, 91, 6269-6274.

9. Lee S.H., Rasiah J.C., J. Phys. Chem., 1996, 100, 1420-1428.

10. Vlček L., Nezbeda I., Mol. Phys., 2003, 101, 2987-2996.

11. Nezbeda I., Vlček L., Int. J. Thermophys., 25, 1037-1049.

12. Vlček L., Nezbeda I., Mol. Phys., 2004, 102, 485-497.

13. Straatsma T.P., McCammon J.A., Ann. Rev. Phys. Chem., 1992, 43, 407-435.

14. Allen M.P., Tildesley D.J. Computer Simulation of Liquids. Oxford, Clarendon Press, 1987.

15. Predota M., Nezbeda I., Cummings P.T., Mol. Phys., 2002, 100, 2189-2200.

16. Vlček L., Nezbeda I., Mol. Phys., 2004, 102, 771-781.

17. Liu W.-B., Li Y.-G., Lu J.-F., Fluid Phase Equilibria, 1999, 158-160, 595-606. 


\title{
Потенціал середньої сили між іонами у безмежно розведених спрощених моделях водних електролітів
}

\author{
Л.Влцек ${ }^{1}$, І.Незбеда ${ }^{1,2}$ \\ 1 Лабораторія термодинаміки Гала Е., Прага, \\ Чеська республіка \\ 2 Фізичний факультет університету Я.Е. Пуркіне, \\ Усті над Лабом, Чеська республіка
}

Отримано 6 січня 2005 р.

Обчислення потенціалу середньої сили для спрощеної моделі 3 короткодіючими взаємодіями (кулонівська взаємодія між іонами і водою замінена взаємодією трикутної ями) розглядається як спроба визначити ефект далекодіючих електростатичних взаємодій у розчинах електролітів. Розміри таких розчинених іонів вибирались таким чином, щоб апроксимувати реальні $\mathrm{NaCl}$, Lil, та CsCl розчини електролітів. Показано, що, незважаючи на нехтування далекодіючими кулонівськими взаємодіями, модель відображає основні характеристики реальних розчинів електролітів, тоді як непряма взаємодія між іонами опосередкована водою, тобто потенціал середньої сили якісно добре узгоджений з результатами реалістичних моделей.

Ключові слова: водні електроліти, проста короткосяжна модель електролітів, примітивна вода, примітивні іони, потенціал середньої сили

PACS: 05.20.Jj 